\title{
INFLUENCE OF FEED DIRECTION AND RATIO ON ELLIPTIC CURVATURE REPRESENTATION ACCuracy During Profile Milling
}

\author{
FilipOWICZ, K. \& KROLIKOWSKI, M.
}

Abstract: Presented experiments concern prediction of machining deviation values of curvilinear profiles, as a dependant on milling parameters. Described prediction was based on the forces values predicted in machining. The results of research concerning problems of predicting the elliptic profile representation accuracy, during profile milling are presented in paper. The practical research was aimed to compare theoretically estimated values of the deviations in selected model and real inaccuracies for assumed parameters and verify quality of selected machining model. The verification aims to create the most accurate model for further research.

Key words: milling, profile milling, milling accuracy.
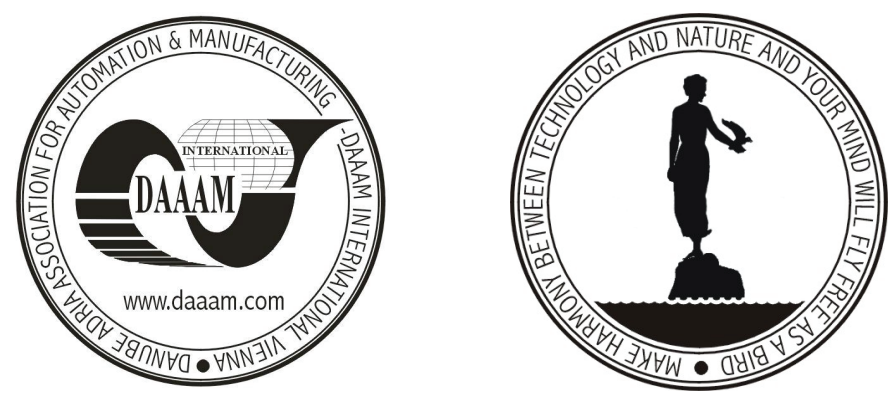

Authors' data: Msc. Eng. Filipowicz K.[rzysztof] Z., Msc. Eng.

Krolikowski M.[arcin] A., Szczecin University of Technology, Poland, krzysztof.filipowicz@ps.pl, Marcin.Krolikowski@ps.pl

This Publication has to be referred as: Filipowicz, K. \& Krolikowski, M. (2006). Influence of Feed Direction and Ratio on Elliptic Curvature Representation Accuracy During Profile Milling, Chapter 18 in DAAAM International Scientific Book 2006, B. Katalinic (Ed.), Published by DAAAM International, ISBN 3-901509-47-X, ISSN 1726-9687, Vienna, Austria

DOI: $10.2507 /$ daaam.scibook.2006.18 